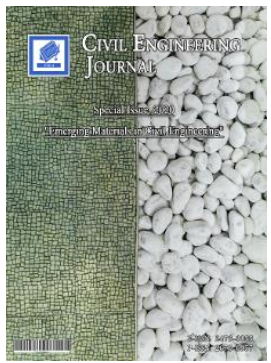

\title{
Impact of Fire on Mechanical Properties of Slurry Infiltrated Fiber Concrete (SIFCON)
}

\author{
Anwar Saad Abbas ${ }^{a^{*}}$, Mohammed Mansour Kadhum ${ }^{\mathrm{a}}$ \\ ${ }^{a}$ University of Babylon, Babylon, Hilla 5100, Iraq.
}

Received 30 May 2020; Accepted 11 September 2020

\begin{abstract}
This research aims to shed light on the fire flame effect on some mechanical properties of SIFCON samples, such as compressive strength, flexural strength and modulus of elasticity and comparing the results with CEN design curve and CEB. Higher temperature resistance is one of the most important parameters affecting the durability and service life of the material. This study comprised of casting and testing SIFCON specimens with $6 \%$ fiber volume before and after exposure to elevated temperatures. Two fire exposure duration of 1 and 2 hours were investigate. In addition to room temperature, Silica fume was used as a partial replacement (10\%) by weight of cement. It was found from the results achieved that after exposure to high temperatures, compressive strength, flexural strength and elastic modulus decreased. The drastically reduction of compressive strength took place with increasing temperature. The residual compressive strength, flexural strength and elastic modulus at $1010{ }^{\circ} \mathrm{C}$ were in the range of $(58.4$ to $80.1 \%),(81.6$ to $78.7 \%)$ and (30.4 to $32.8 \%$ ) respectively. The compressive strength test results of this study together with results obtained by other investigators were compared with CEB strength-reduction curve and that of CEN. It was noticed that the test results agreed with CEN design curve rather than with that of CEB.
\end{abstract}

Keywords: Completely Decomposed Granite; Soil Mineralogy; Micro-fabric.

\section{Introduction}

The production of concrete technology is becoming more advanced as engineers have started using concrete in their designs other than just normal concrete. Given the very high compressive strength values and other high or ultrahigh efficiency advantages. In general, such materials remain a brittle composite material. The incorporation of adequate fiber increases the tensile strength with increased ability to deform and therefore offers ductility. In 1979 by Lankard Materials Laboratory, Columbus, Ohio, USA, integrating significant amounts of steel fibers into composite reinforced cement [1]. SIFCON can be considered as a special form of reinforced fiber concrete (FRC) with a high fiber content. Molded with cement-based slurry or flowing mortar, and infiltrated. The SIFCON production involves sprinkling the fibers in the mold to their maximum capacity first. Then, cement-based slurry penetrates the fibre network. To ensure proper fiber bed slurry infiltration Vibration is also required [2, 3]. The amount of fibers will vary from 5 to 20 per cent and is a feature of Various parameters, such as fiber length, diameter and aspect ratio; their orientation; the process used in the packaging; Mold size; and vibration range. SIFCON shows good strength and ductility in comparison with traditional FRC with a Large volume steel fibre fraction [4].

* Corresponding author: harry.wizerd@gmail.com

http://dx.doi.org/10.28991/cej-2020-SP(EMCE)-02

(C) 2020 by the authors. Licensee C.E.J, Tehran, Iran. This article is an open access article distributed under the terms and conditions of the Creative Commons Attribution (CC-BY) license (http://creativecommons.org/licenses/by/4.0/). 
Research into SIFCON's mechanical properties proved excellent Material properties with respect to strength (tension, compression and shear), ductility and energy absorption Capabilities [5]. By volume implemented for SIFCON, distributed at random. After 28 days curing the compressive and splitting tensile strength test results were

The cement-based slurry used consisted of a mixture of various percentages of cement, fly ash, silica fumes and eco-sand to soil. In the present study, the water cement ratio of 0.5 and super plasticizer $2 \%$ by weight of cement was adopted. The $6 \%$ fiber content $(68.5,65,66.5) \mathrm{MPa}$ and $(9.86,9.2,8.87) \mathrm{MPa}$, respectively, for the three slurry mix ratio. The researchers found that the members of SIFCON are much stronger than traditional concrete.

Kim and Choi [6], investigate SIFCON's compression and tensile properties. They used hooked end steel fibers in the mixture, with fraction of varying from $4 \%$ to $10 \%$. The water-to - cement ratio is kept constant at 0.4 . By weight of cement, the silica fume was added 10 per cent. The test results showed that SIFCON 's compressive strength was roughly (1.59 to 2.68) times compared to the cement paste. The SIFCON ductility and toughness was also substantially increased with the increasing in volume of fibers.

Pradeep and Sharmila (2015) [7], investigated the mechanical properties and flexural properties of SIFCON members are evaluated and they are compared with conventional concrete of grade M40. The compression strength of SIFCON was found to be $33 \%$ more than conventional concrete and $102.4 \%$ more than SIFCON specimens without fiber. The flexural strength of SIFCON was $179 \%$ more than conventional concrete and $232 \%$ more than SIFCON specimens without fiber. The parameters like ductility, stiffness and energy absorption were higher for SIFCON section than conventional concrete. Thus, this study shows that SIFCON can be used as an effective alternative in special concreting purposes or where the concrete or conventional SFRC cannot perform as expected/required or in situations where such high strength is required.

Exposure to high temperatures, mainly caused by accidental fires, is one of the most severe conditions for building and structural damage. The fire performance is important and necessitates investigation prior to proper usage in construction industries Liu and Huang (2009) conducted a series of fire resistance tests and found that the residual compressive strength decreases with the increase in fire duration [8]. The fire resistance and post-heat exposure behavior of the structural component depends on the thermal and mechanical properties of the composite materials. Elasticity is one of the important material properties that play an important role in the structural behavior of concrete elements both before and after exposure to elevated temperatures [9]. For reasons such as fire or explosion, SIFCON used to strengthen work and military systems may be exposed to high temperatures. High temperature exposure is one of the most important physical degradation processes affecting the life of cement-based composites [10]. Many researchers studied the effect of fire on concrete; reinforced concrete members are concentrated on exposing such members to high temperatures in special ovens. They worked on the strength and deformation properties at elevated temperatures. Such conditions do not represent the effects due to real fires, whereas, subjecting these members to direct fire flame is assumed to simulate the conditions happening in real fires [11]. From this point of view. The primary objective of this research is to perform an experimental investigation to study the effect of real fire exposure on the compressive strength and elastic modulus of SIFCON samples after high temperature exposure.

Beglarigale et al. (2016) [10] studied SIFCON's high-temperature composite flexural performance. The scope of this research was subjected to normal or steam cured slurry infiltrated fiber concrete (SIFCON) and slurry samples at $300,600,750$ and $900{ }^{\circ} \mathrm{C}$. Exposing the samples to $300^{\circ} \mathrm{C}$ improved mechanical performance whereas higher temperatures have detrimental effects on SIFCON composites such as loss in the steel fibers cross section and degradation of $\mathrm{C}-\mathrm{S}-\mathrm{H}$ structure. This study. Exposing the specimens to $300{ }^{\circ} \mathrm{C}$ enhanced the mechanical performance, while higher temperatures have detrimental effects on the SIFCON composites such as the loss in the cross section of steel fibers and the destruction of $\mathrm{C}-\mathrm{S}-\mathrm{H}$ structure.

Hassan (2006) [12], proved that the compressive strength of concrete with steel fiber at (1.7\%) before heating is higher than that in concrete without steel fiber. The compressive strength between $\left(300\right.$ and $\left.400^{\circ} \mathrm{C}\right)$ for the concrete with and without fiber were proven to be convergent. The residual compressive strength of the plain was found to be higher than those of steel fibrous concrete at temperatures less than or equal to $400^{\circ} \mathrm{C}$.

Hashim and Kadhum (2020) [13], investigated the effect of fire flame on the behavior of Slurry Infiltrated Fiber Concrete (SIFCON) before and after exposure to fire. An experimental program was carried out with $6 \%$ fiber content and by two fire exposure durations of 2 and 3 hours are examined. In addition to room temperatures, three temperature ranges of 400,600 and $900^{\circ} \mathrm{C}$ have been tested. The test results show that the compressive strength and elastic modulus decreased after exposure to high temperatures and the drastically reduction of compressive strength took place with increasing temperature above $600{ }^{\circ} \mathrm{C}$. Also, the residual compressive strength and elastic modulus at $900{ }^{\circ} \mathrm{C}$ were in the range of (52.1 to $59.6 \%$ ) and (30.6 to $34.1 \%$ ) respectively.

The primary aim of this research is to study the effect of higher temperature on SIFCON's mechanical properties such as compressive strength and modulus of elasticity. For a maximum temperature up $1000^{\circ} \mathrm{C}$ and how this higher temperature effects on the aforementioned properties. Figure 1 show the overall experimental investigation of research. 


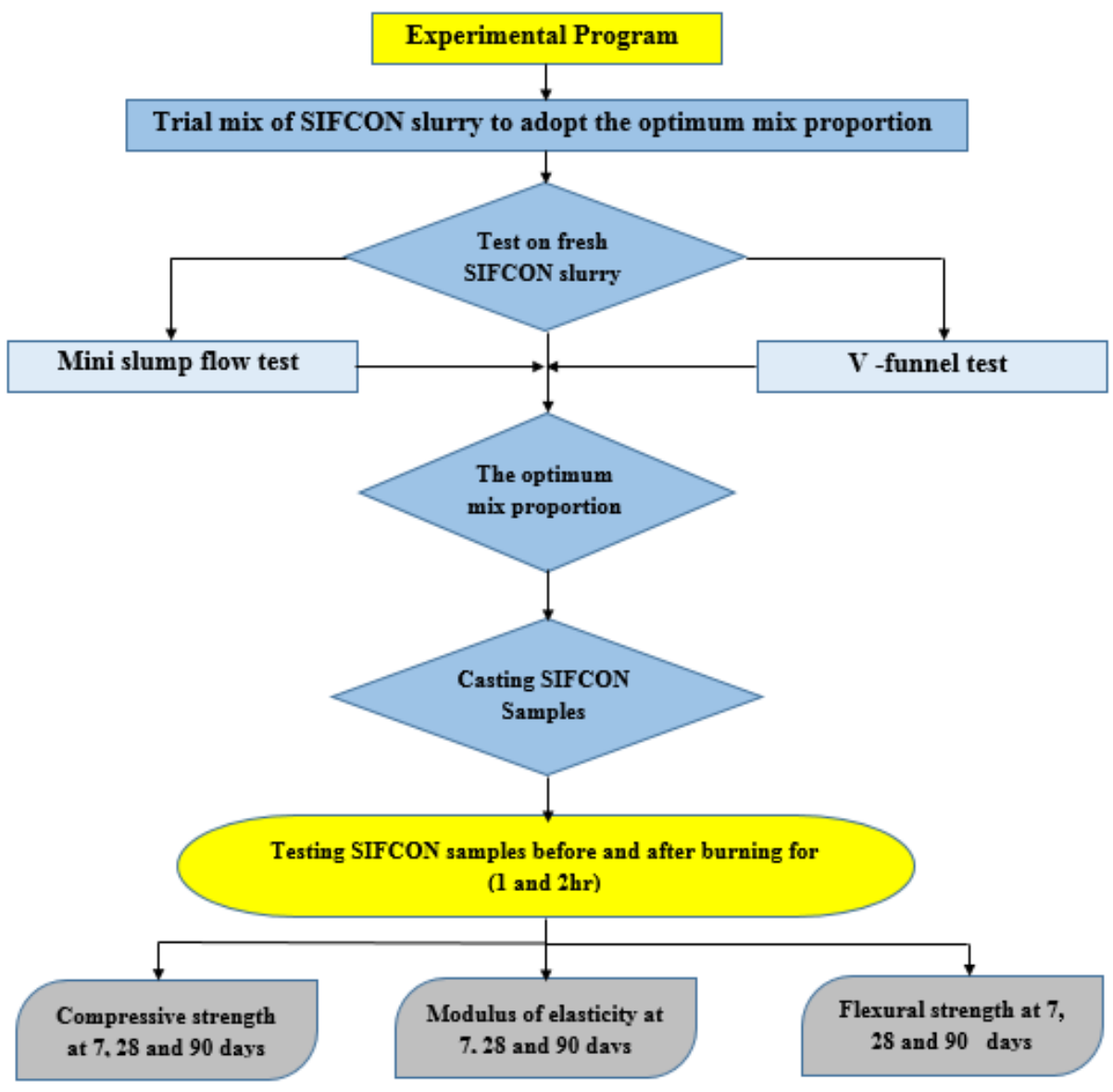

Figure1. Flowchart of the research plan

\section{Materials and Methods}

\subsection{Cement}

The type of cement used in this study was Ordinary Portland Cement (OPC) Type I which complies with the ASTM C150-18 specification.

\subsection{Fine Aggregate}

AL-Ukhaider natural sand with a maximum size of $1.18 \mathrm{~mm}$ was used in this investigation and a specific gravity of 2.60 is used as a fine aggregate for SIFCON. It must be small enough to achieve maximum penetration through the dense steel fiber without clogging up. Figure 2 shows natural sand gradation curve in accordance with (IQS No.45/1984).

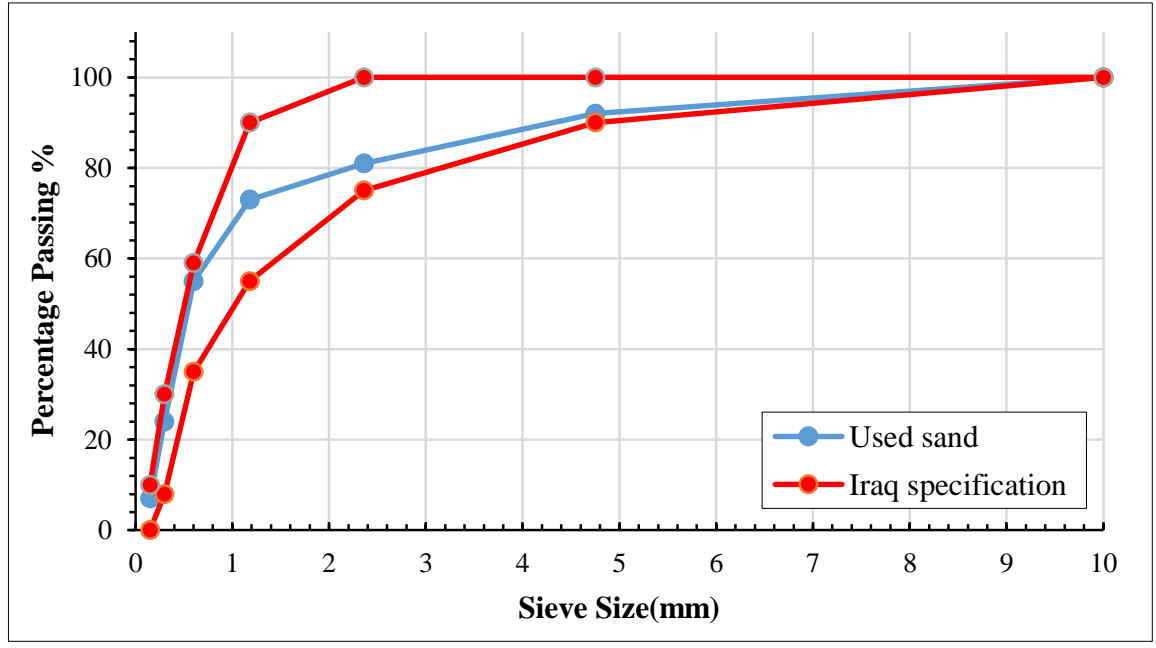

Figure 2. The grading curve of the original sand 


\subsection{Micro Silica Fume (SF)}

The silica fume used in this research; which is commercially known as Mega Add MS (D) from chemical company (CONMIX), and it was utilized in this investigation as a partial replacement (10\%) by weight of cement. Silica fume improves the micro structure of the cement paste and makes it of more resistance to any type of external influence.

\subsection{High-Range Water Reducing Admixture (HRWRA)}

The high-performance water reducing admixture used in this study is third-generation super plasticizer for concrete and mortar, known commercially as (Hyperplast PC200), it is imported from the company (DCP), and complies with (ASTM C494 / C494M).

\subsection{Steel Fibers}

Straight steel fiber (micro steel fiber) was used in this work, with (13) mm length and (0.2) mm diameter. This type of steel fibers was manufactured by the (Ganzhou Daye Metallic Fibers Co., Ltd, China) and imported in $25 \mathrm{Kg}$ bags. Figure 3 display the micro steel fiber was used in this research.

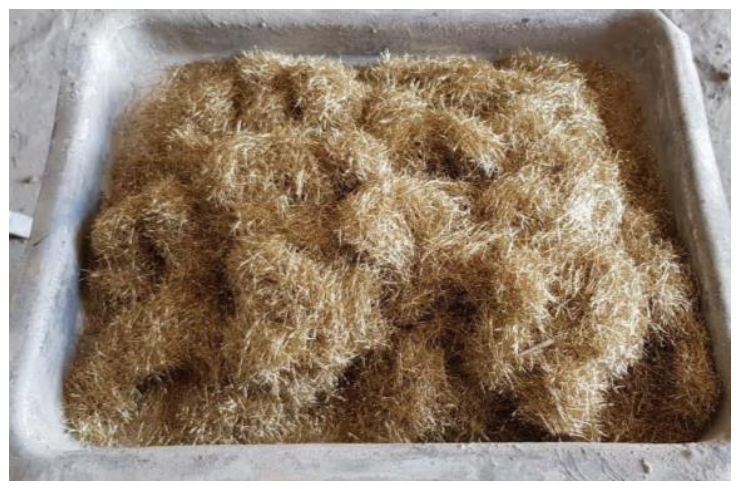

Figure 3. Micro steel fiber used

\subsection{Mix Proportion}

A number of trail slurry mixtures were used to find a suitable mixture with ideal features in terms of Viscosity, fluidity and ability to fill the fiber network without bleeding or segregation or honeycomb, which responsible for a dramatic reduction in SIFCON's mechanical properties. The properties of the mixture are indicated in the Table 1. Workability of SIFCON slurry is calculated by the mini-slump flow test in compliance with ASTM C1437-15 as 260 $\mathrm{mm}$. Viscosity of the slurry is also assess by Mini V-funnel test and the time measured was 11 second.

Table 1. Mix design for SIFCON matrix for $1 \mathrm{~m}^{3}$

\begin{tabular}{cc}
\hline Composition Type & Mix Proportion \\
\hline Cement & $872.1\left(\mathrm{~kg} / \mathrm{m}^{3}\right)$ \\
SF & $96.9\left(\mathrm{~kg} / \mathrm{m}^{3}\right)$ \\
Sand & $969\left(\mathrm{~kg} / \mathrm{m}^{3}\right)$ \\
Steel Fibre & $6(\%)$ \\
(SP) by the Weight of Cementitious & $3.7(\%)$ \\
Water/binding & 0.33 \\
Mini-slump flow & $364(\mathrm{~mm})$ \\
V-funnel time & $11(\mathrm{~s})$ \\
\hline
\end{tabular}

\subsection{Procedure of Casting}

A multi-layer method is used to cast samples of SIFCON, as shown in Figure 4. Each layer is $10 \mathrm{~cm}$ thick. This technique initially involved placing and packing randomly oriented fibers and sprinkling them by hand Mold to a depth of $10 \mathrm{~cm}$, then fill the mold with a slurry up to this point as shown in Figure 4A. To ensure infiltration through the fibre, the slurry must be sufficiently flowable. Then the fibers in the mould were compacted using a steel rod with a tapered end, see Figure 4B to avoid honeycombing or voids. This process was repeated (for each layer) where the whole mold was stuffed with the volume fraction of fibers. The samples have been covered with nylon sheet after 
casting to reduce the possibility of shrinkage cracks caused by evaporation of Water and left for 24 hours in laboratory as shown in Figure 4C.

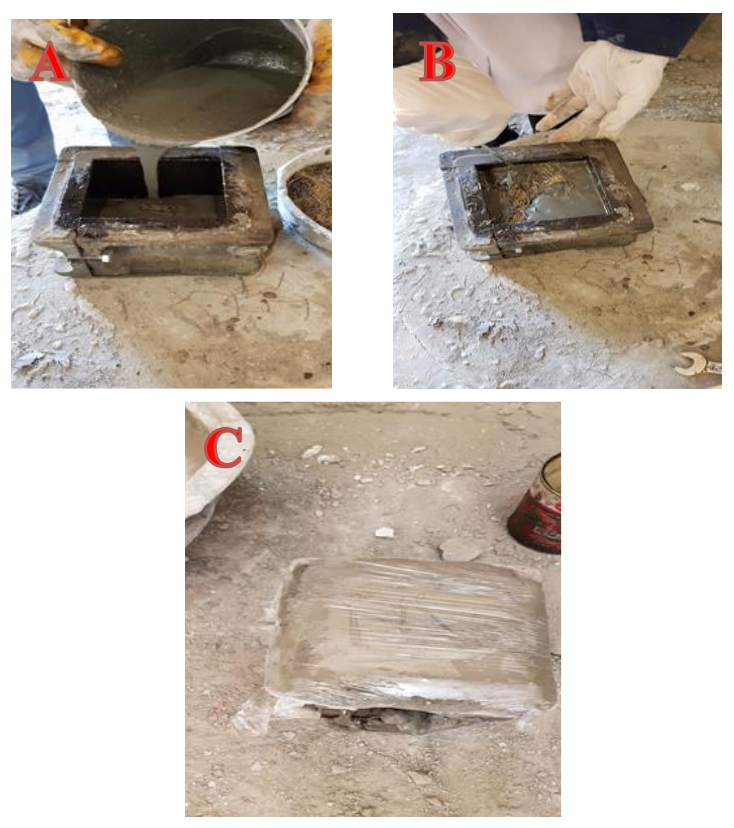

Figure 4. The procedure of casting SIFCON specimen

\subsection{Test Methods}

\subsubsection{Temperature Load}

To provide temperature load a furnace used, the samples were heated in the furnace according to the standard fire curve recommended of (ASTM E-119) at temperature levels $\left(927^{\circ} \mathrm{C}\right.$ for $1 \mathrm{hr}$. and $1010{ }^{\circ} \mathrm{C}$ for $2 \mathrm{hr}$.).

The fire exposure tests were performed at Babylon University Faculty of Engineering in the laboratory of structural material properties. The dimensions of the manufactured furnace are $1500 \mathrm{~mm}$ length, $1500 \mathrm{~mm}$ width and $1250 \mathrm{~mm}$ height. The thickness of all walls for every side is fixed at $250 \mathrm{~mm}$, the principal structure is built with refractory bricks and mortar and has a small opening for giving suitable burners air, and the cover of the furnace has been made with $8 \mathrm{~mm}$ thick insulating plate to maintain the fire temperature. The primary aim of the furnace chamber is to raise the levels of temperature of the exposure to fire and to keep it constant for the required duration. To control the temperature of fire, the process of heating comprises of the equipment (see Figure 5). The burners set comprises of group liquefied petroleum gas burners, all burners were connected together in one pipeline as shown in Figure 5.

The real time-temperature curve was programmed by MATLAB program so that the heat thermocouple inside the furnace was connected to the computer to record the temperature values directly with the time. Then at the end of the burning process the temperatures and times data are stored with the final shape of the time-temperature curve on the computer. Figure 6 illustrates an example of the time-temperature curve drawing by MATLAB program.
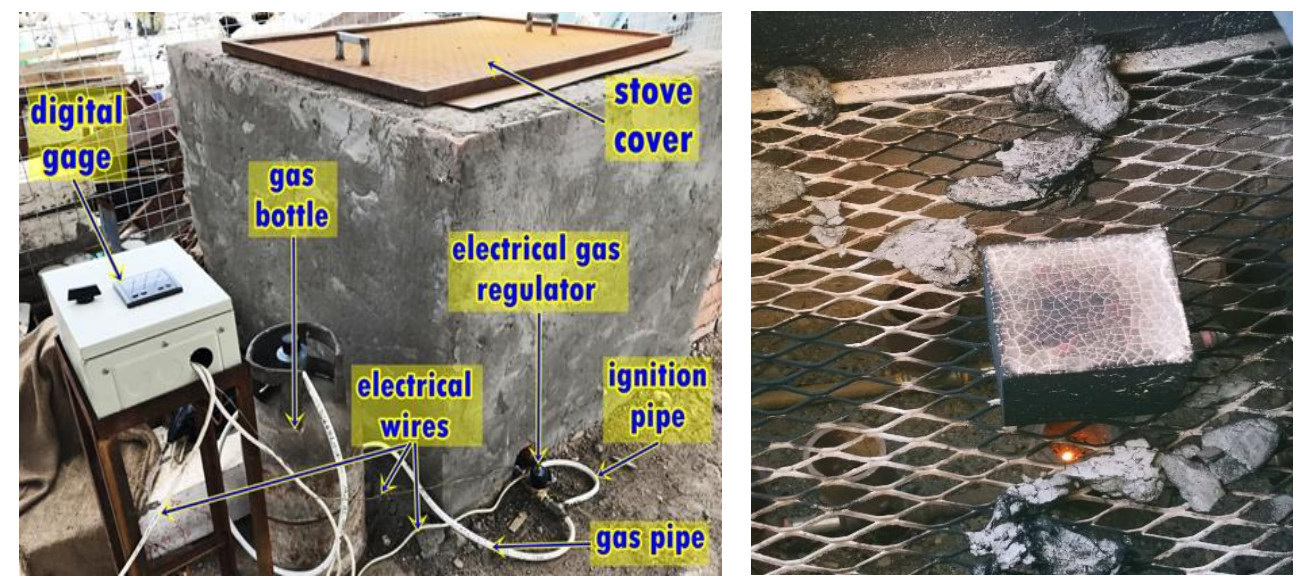

Figure 5. Details of the brick furnace 


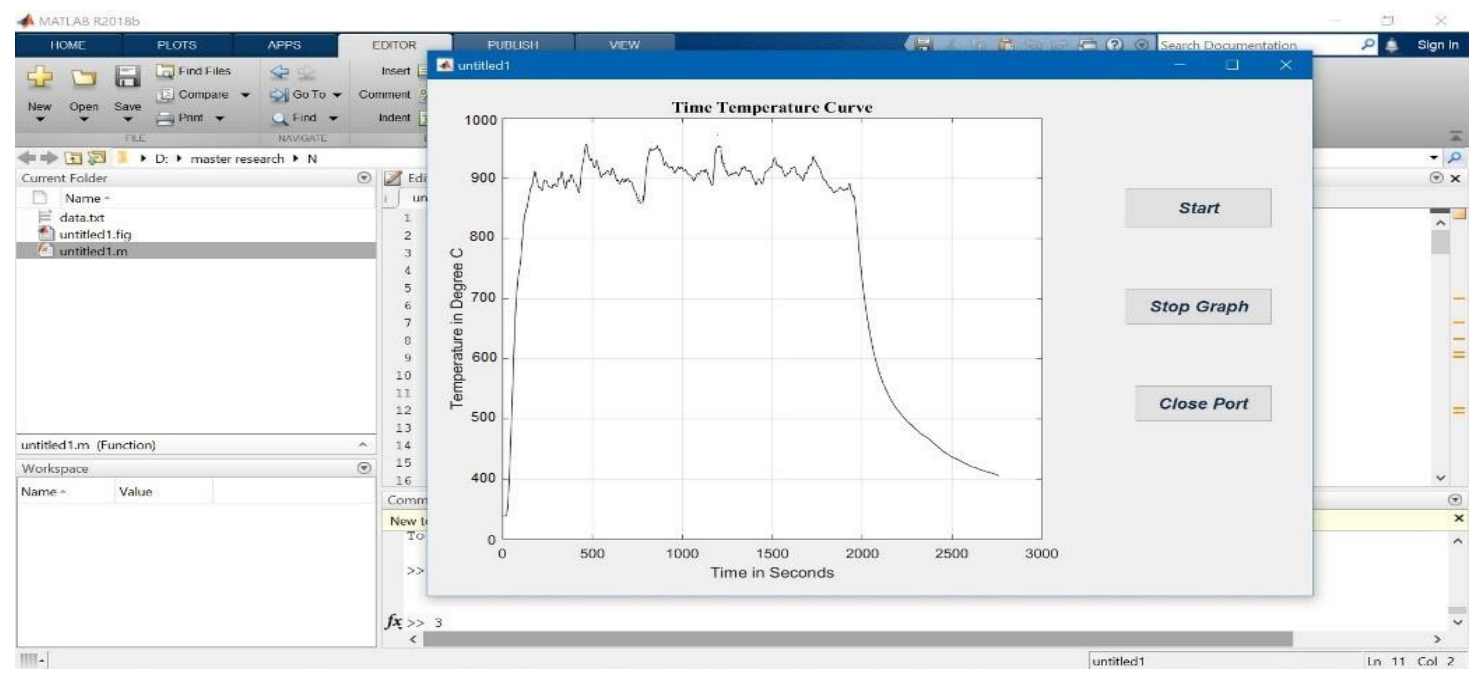

Figure 6. An example for record and drawing of the time-temperature curve by MATLAB program

\subsubsection{Compressive Strength}

Three cubes specimens are utilized to measure the compressive strength $\left(\mathrm{f}_{\mathrm{cu}}\right)$. Three cubes of $(100 \times 100 \times 100 \mathrm{~mm})$ are utilized for each test results and the average reading for a single age of these three cubes is taken. Compressive strength is tested at the age of 7, 28 and 90 days according to ASTM C 109/C 109M.

\subsubsection{Flexural Strength}

This test is utilized to identify material flexural strength or flexural modulus. This test is more agreeable compared with a tensile test. Each prism was simply supported and subjected to a two-point loading using testing machine with a capacity of $(1900 \mathrm{kN})$ as shown in Figure 7 , and the average of three prisms of $(50 \times 50 \times 300 \mathrm{~mm})$ were tested for each consequence according to ASTM (348-19) at 7, 28 and 90 days.
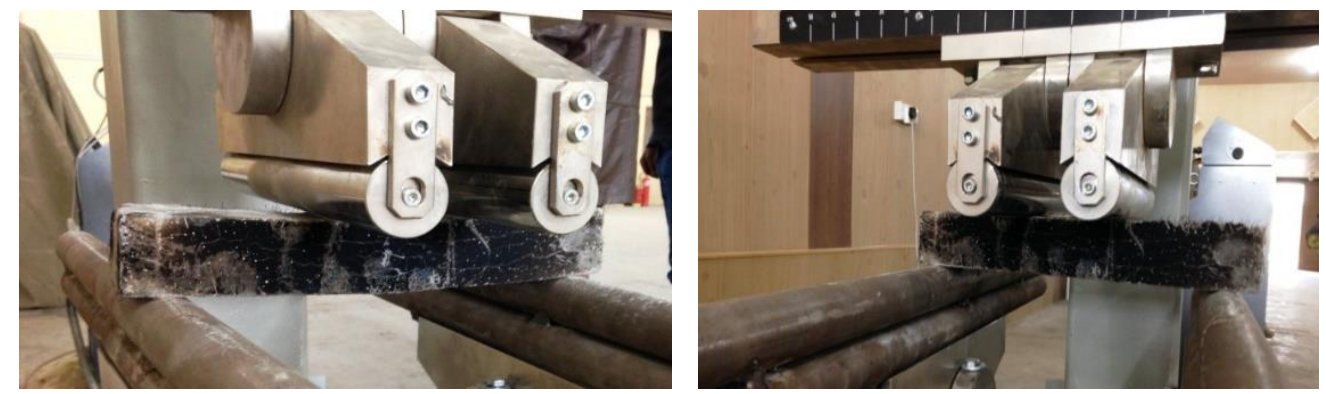

Figure 7. Flexural strength test and machine

\subsubsection{Modulus of Elasticity}

The static modulus of elasticity of concrete was also measured on cylindrical samples with a height of $200 \mathrm{~mm}$ and a diameter of $100 \mathrm{~mm}$ and according to ASTM C469. For each sample, the top surface of cylinder was well finished and smoothed by using electric grinding machine to prevent any loss of strength. The samples were tested at ages $(7$, 28 and 90 days) and the average of three samples was taken for each test results.

\section{Results and Discussions}

In this research, compressive strength, Flexural strength and modulus of elasticity of slurry infiltrated fibrous concrete (SIFCON) were investigated both at ordinary temperatures and after exposure to high temperatures.

\subsection{Compressive Strength}

Table 2 demonstrates the SIFCON compressive strength before and after burning. In this table, each value reflects the average values collected from the 3 cubes test in order to minimize the anticipated mistake in any measured consequence. 
Table 2. Compressive strengths results of SIFCON samples before and after exposure to fire flame

\begin{tabular}{|c|c|c|c|}
\hline \multirow{3}{*}{ Age (days) } & \multicolumn{3}{|c|}{ Compressive Strength $f_{\text {cu }}$ (MPa) } \\
\hline & \multirow{2}{*}{$25^{\circ} \mathrm{C}$} & $1 \mathrm{hr}$. fire exposure & $2 \mathrm{hr}$. fire exposure \\
\hline & & $927^{\circ} \mathrm{C}$ & $1010{ }^{\circ} \mathrm{C}$ \\
\hline 7 & 69.34 & 44.18 & 38.69 \\
\hline $\mathrm{f}_{\mathrm{cu}} / \mathrm{f}_{\mathrm{cu}}\left(\mathrm{T}=25^{\circ} \mathrm{C}\right) \%$ & 100 & 63.7 & 55.79 \\
\hline Change in $\mathrm{f}_{\mathrm{cu}} \%$ & 0 & -36.28 & -44.2 \\
\hline 28 & 98.64 & 63.74 & 57.62 \\
\hline $\mathrm{f}_{\mathrm{cu}} / \mathrm{f}_{\mathrm{cu}}\left(\mathrm{T}=25^{\circ} \mathrm{C}\right) \%$ & 100 & 64.6 & 58.41 \\
\hline Change in $\mathrm{f}_{\mathrm{cu}} \%$ & 0 & -35.3 & -41.5 \\
\hline 90 & 123.15 & 104.2 & 98.7 \\
\hline $\mathrm{f}_{\mathrm{cu}} / \mathrm{f}_{\mathrm{cu}}\left(\mathrm{T}=25^{\circ} \mathrm{C}\right) \%$ & 100 & 84.6 & 80.14 \\
\hline Change in $\mathrm{f}_{\mathrm{cu}} \%$ & 0 & -15.38 & -19.85 \\
\hline
\end{tabular}

Figure 8 reveals the effect of fire temperature on the compressive strengths of SIFCON samples. From this Figure, it can be concluded that the drastically reduction of compressive strength took place with increasing temperature. This reduction could be explained by the decomposition of $\mathrm{C}-\mathrm{S}-\mathrm{H}$ and $\mathrm{CH}$ hydrates resulted in a decrease in the strength. Further reduction was obtained due to the bonds between cement past and steel fibres were severely deteriorated due to uneven expansion among them. The severe cracking at $1010^{\circ} \mathrm{C}$ resulted in more than (45\%) loss in compressive strength.

From previous table and figure, it can be observed that more reduction occurs in compressive strengths of SIFCON under fire temperature $1010^{\circ} \mathrm{C}$ ( 2 hrs. duration of exposure).

This can be attributed to the increase in the amount of cracks formed due to exposure to fire and the physicochemical transformation in concrete constituents during burning will yield strength loss.

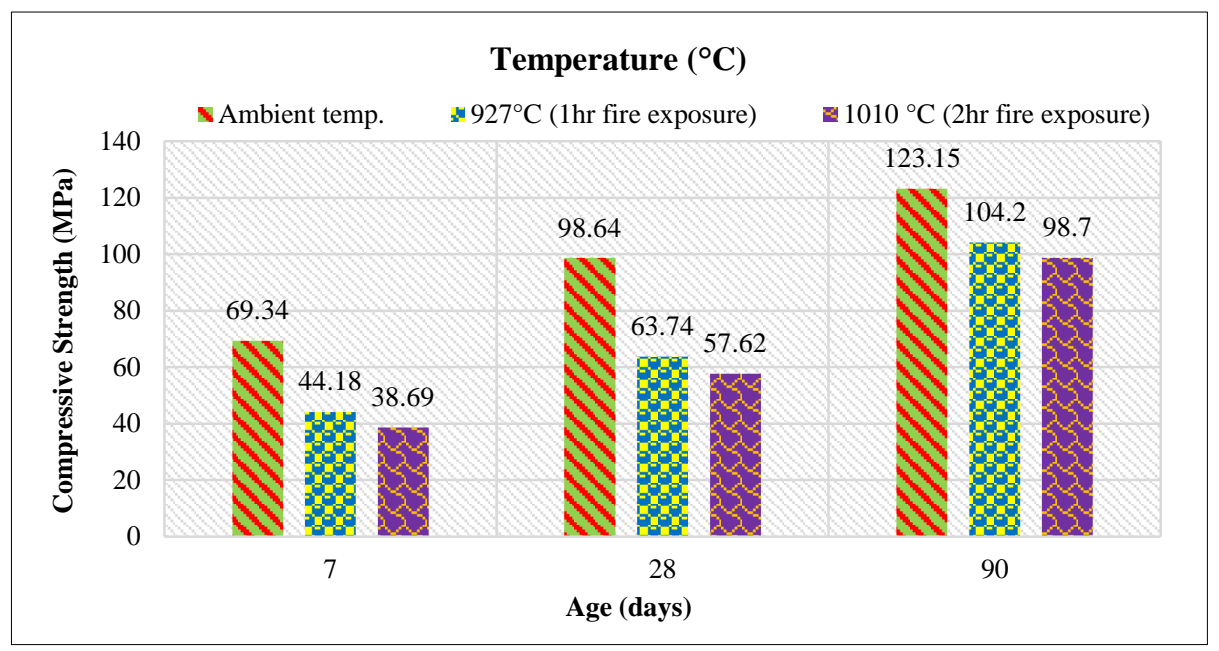

Figure 8. Compressive strength of SIFCON after exposure to fire flame

Figure 9 shows the comparison between the residual in compressive strength after exposure to fire flame obtained in this study with the residual in compressive strength of different concrete obtained from different studies as follow:

- Fitting model without fiber content for normal strength concrete (NSC) [14].

- Fitting model for plain high performance concrete (HPC) [15] .

- Steel fiber-reinforced normal strength concrete (SFRC) fitting model [16].

- Experimental results of reactive powder concrete (RPC) [17].

- Experimental results of SIFCON concrete [13]. 


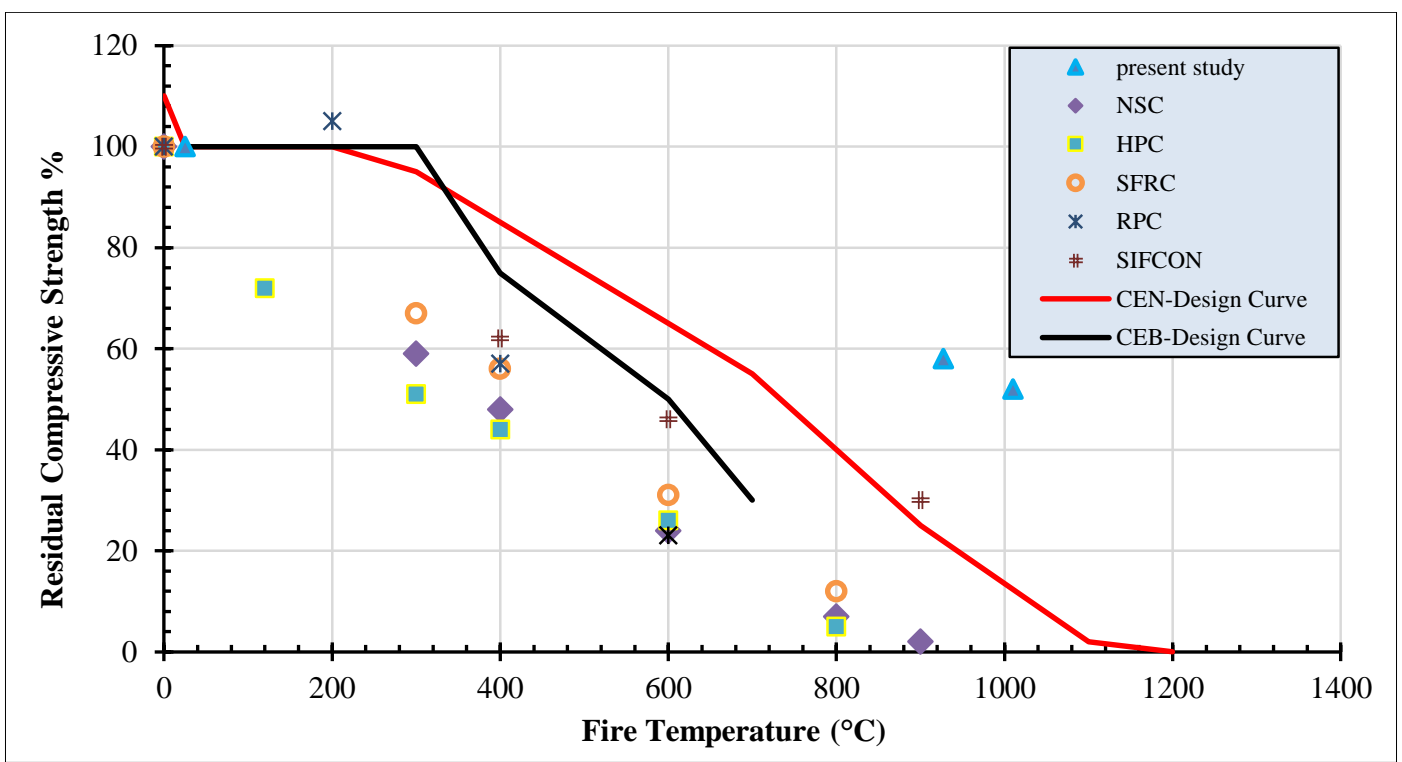

Figure 9. Comparison of residual compressive strength values of SIFCON and the recommended design curves of CEN and CEB

It's clear from Figure 9, that SIFCON performs better than other traditional types of concrete due to its superior microstructure and effective role of steel fibers to resist spalling and crack propagation at high temperatures, resulted in improved compressive strength. Where the test samples were done with high temperatures up $1000^{\circ} \mathrm{C}$ while most researchers reach the highest temperature of $900^{\circ} \mathrm{C}$.

In the present study some of the test results of residual compressive strength were found to lie between CEB and CEN curves, while other results diverged from the CEB curve and converged to the CEN curve especially at temperature lower than $927^{\circ} \mathrm{C}$. At $927^{\circ} \mathrm{C}$ and $1010^{\circ} \mathrm{C}$ fire temperature, the test results were found to be near the CEN curve only. From the figure, it can be concluded that the test results of the current study have better agreement with CEN design curve than with CEB curve.

\subsection{Visual Observations}

The appearance of the cube samples after fire flame exposure from fire durations are demonstrated in Fig. 9, the pictures of the fire exposed samples displaying distinct micro cracks appearances without the appearance of spalling at different temperature levels taken by HD digital camera. During the tests, special heed was drowning to visual observations. The following are some of the remarking's that were registered:

- All the samples were noticed after being exposed to the realistic fire flame forfeit some of their aestheticism value with the increasing fire temperature, which is clearly a factor to be consider.

- During the experimental test, slight cracks came into sight on the samples at $400^{\circ} \mathrm{C}$ and additional and wider cracks showed at $900^{\circ} \mathrm{C}$ (Figure 10).

- As exposure to fire temperature continued, discoloration of the samples was observed at $1000^{\circ} \mathrm{C}$ (see Figure 11 ). The samples completely lost their brightness.

- Partially no surface cracks were observed up to $800^{\circ} \mathrm{C}$. According to our observations, surface cracking and the spalling of cover were influenced by period of exposure to real fire flame. The decolouration of the surface samples was noticed by Kadhum (2013), Kadhum et al. (2011) and Kadhum and Mohamed (2017) [18-20].
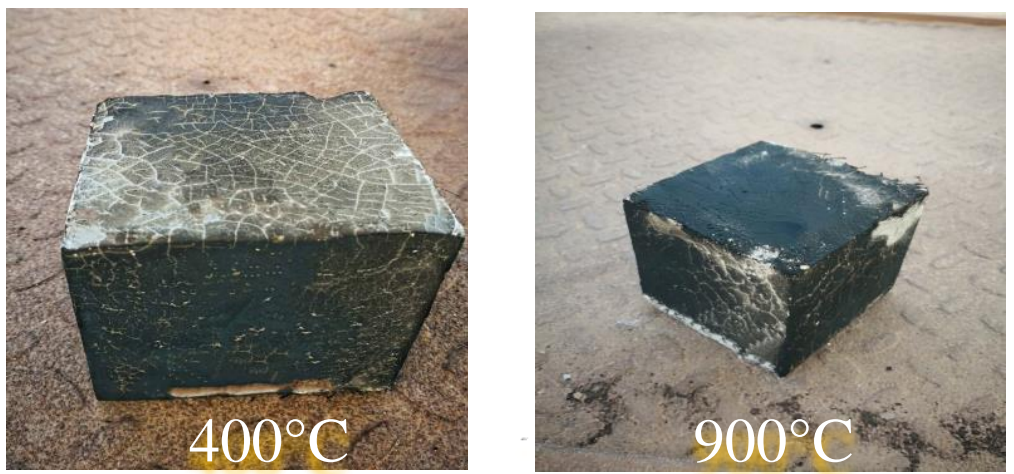

Figure 10. The appearance of cube samples after fire flame exposure 


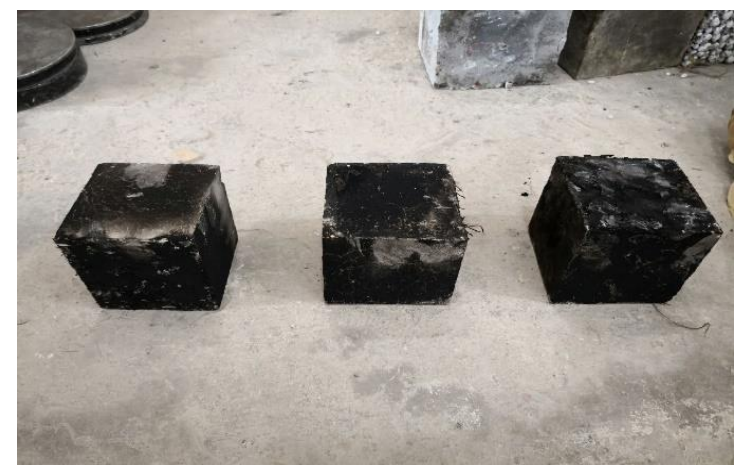

Figure 11. Discoloration of the samples observed after fire flame exposure

\subsection{Static Modulus of Elasticity}

The modulus of elasticity is strongly influenced by the concrete materials and their proportions. An increase in the modulus of elasticity is expected with an increase in compressive strength since the slope of the ascending branch of the stress-strain diagram becomes steeper.

Figure 12 depicts the relationship between modulus of elasticity and fire flame temperature levels for SIFCON samples. From the results of Table 3, it can be concluded that the reduction in values of modulus of elasticity is more significant than in compressive strength at identical fire flame temperatures. The reduction of the modulus of elasticity is due to the breakage of bonds in the microstructure of the cement paste and the differential movement between the cement paste and the aggregate, which take place when the SIFCON subjected to high temperatures of firing process.

Table 3. Test values of elastic modulus of SIFCON samples before and after exposure to fire flame

\begin{tabular}{cccc}
\hline & \multicolumn{3}{c}{ Modulus of Elasticity Ec (GPa) } \\
\cline { 2 - 4 } Age (days) & $\mathbf{2 5}{ }^{\circ} \mathbf{C}$ & $\mathbf{1 ~ h r . ~ f i r e ~ e x p o s u r e ~}$ & $\mathbf{2}$ hr. fire exposure \\
\cline { 2 - 4 } & & $\mathbf{9 2 7}{ }^{\circ} \mathbf{C}$ & $\mathbf{1 0 1 0}{ }^{\circ} \mathbf{C}$ \\
\hline \hline Ec/Ec $\left(\mathrm{T}=25^{\circ} \mathrm{C}\right) \%$ & 24.27 & 8.79 & 29.62 \\
Change in Ec $\%$ & 100 & 36.21 & -70.3 \\
\hline 28 & 0 & -63.7 & 9.01 \\
Ec/Ec $\left(\mathrm{T}=25^{\circ} \mathrm{C}\right) \%$ & 29.56 & 11.1 & 30.48 \\
Change in $\mathrm{Ec} \%$ & 100 & 37.55 & -69.5 \\
\hline 90 & 0 & -62.4 & 11.32 \\
Ec/Ec $\left(\mathrm{T}=25^{\circ} \mathrm{C}\right) \%$ & 34.43 & 13.09 & 32.87 \\
Change in Ec $\%$ & 100 & 38.01 & -67.1 \\
\hline
\end{tabular}

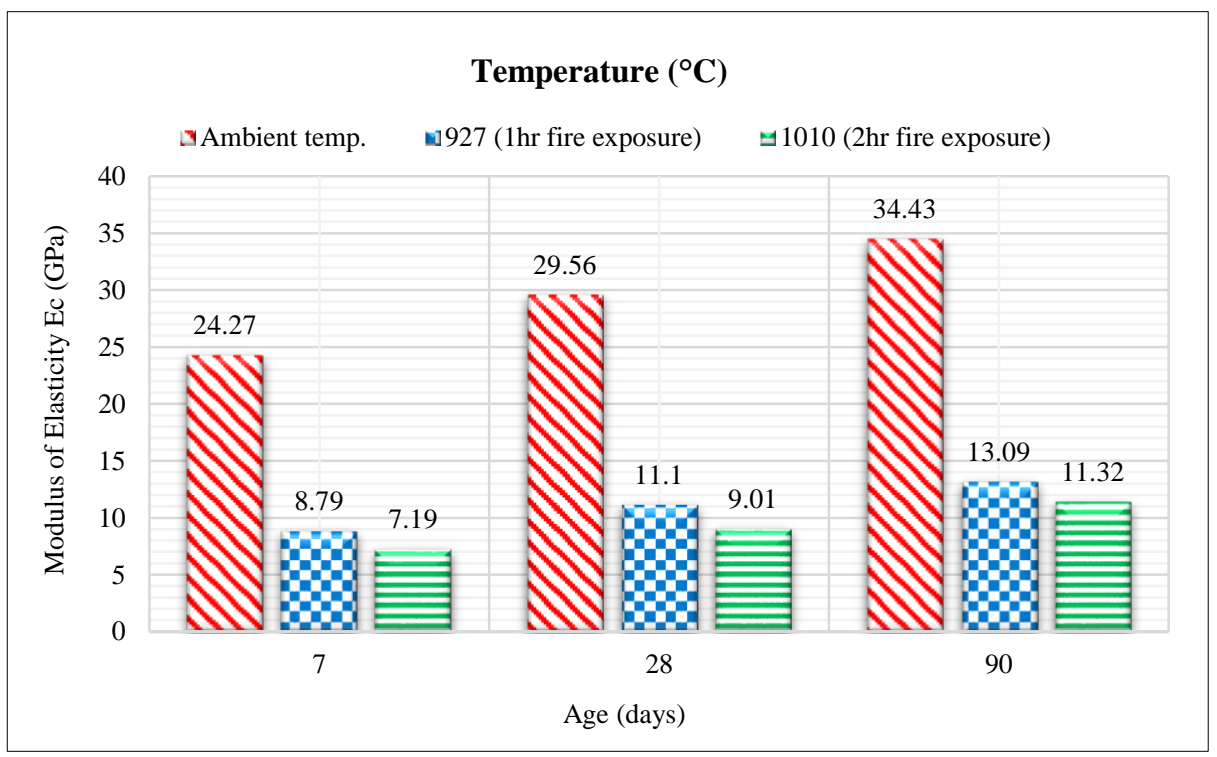

Figure 12. Fire flame effect of on elastic modulus of SIFCON samples 
In Figure 13, the ratio of modulus of elasticity at elevated temperature to corresponding unheated modulus of elasticity has been plotted along with those computed from experimental values of other type of concrete obtained from relevant literature.

- Fitting model without fiber content for normal strength concrete (NSC) [14].

- Fitting model for plain high performance concrete (HPC) [15] .

- Steel fiber-reinforced normal strength concrete (SFRC) fitting model [16].

- Experimental results of reactive powder concrete (RPC) [17].

- Experimental results of SIFCON concrete [13].

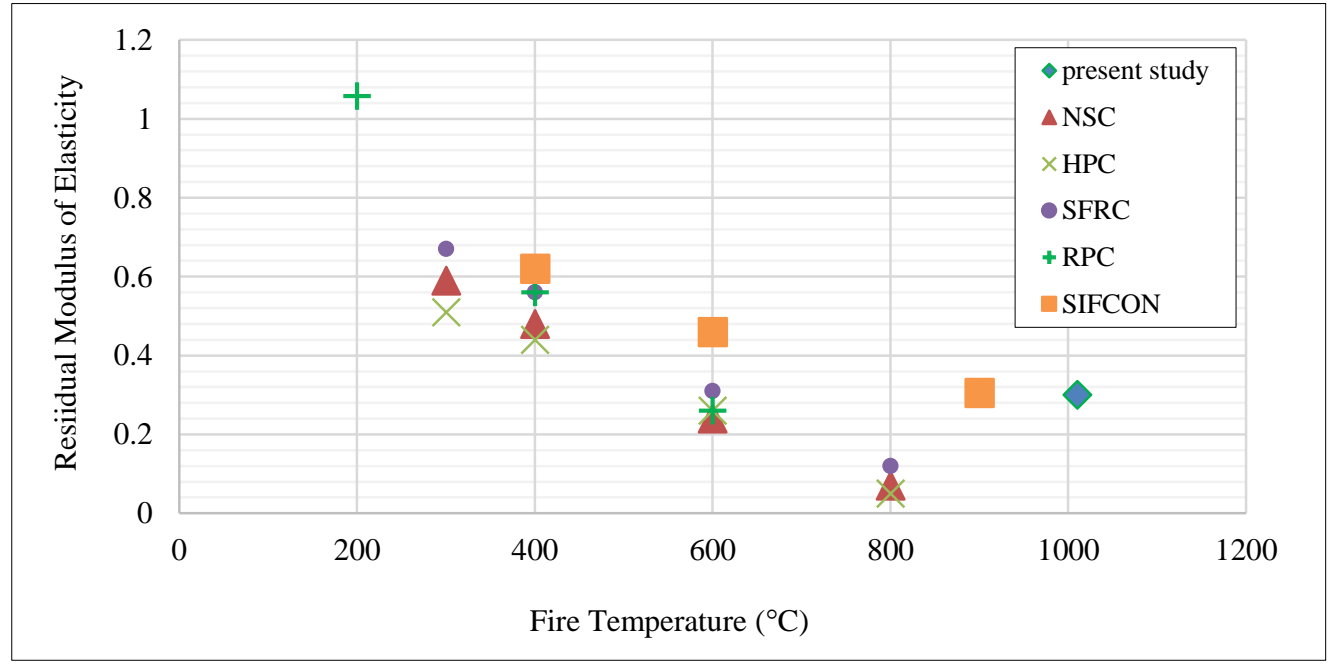

Figure 13. Comparison of elastic modulus values at 28 days with other types of concrete for different researchers

It is evident from Figure 13, that the elastic modulus of SIFCON samples at higher temperatures performs better due to its superior microstructure and effective role of high content of steel fibers to resist spalling and crack propagation at high temperatures.

\subsection{Flexural strength (Modulus of Rupture)}

The flexural strength values of SIFCON specimens at different ages are presented in Table 4, the same procedure which used in the calculation of compressive strength before and after exposure to fire flame was used in this test. Each value represents the average values of three prismatic samples in order to reduce the expected error in any measured result and plotted in Figure 14.

Table 4. Test results of prisms flexural strength of SIFCON samples before and after exposure to fire flame

\begin{tabular}{|c|c|c|c|}
\hline \multirow{3}{*}{ Age (days) } & \multicolumn{3}{|c|}{ Flexural strength (MPa) } \\
\hline & \multirow{2}{*}{$25^{\circ} \mathrm{C}$} & $1 \mathrm{hr}$. fire exposure & $2 \mathrm{hr}$. fire exposure \\
\hline & & $927^{\circ} \mathrm{C}$ & $1010{ }^{\circ} \mathrm{C}$ \\
\hline 7 & 14.62 & 11.97 & 10.2 \\
\hline $\mathrm{fr} / \mathrm{fr}\left(\mathrm{T}=25^{\circ} \mathrm{C}\right) \%$ & 100 & 81.87 & 69.76 \\
\hline Change in $\mathrm{fr} \%$ & 0 & -18.1 & -30.2 \\
\hline 28 & 17.53 & 15.41 & 14.32 \\
\hline $\mathrm{fr} / \mathrm{fr}\left(\mathrm{T}=25^{\circ} \mathrm{C}\right) \%$ & 100 & 87.9 & 81.68 \\
\hline Change in fr $\%$ & 0 & -12.1 & -18.3 \\
\hline 90 & 22.34 & 19.85 & 17.59 \\
\hline $\mathrm{fr} / \mathrm{fr}\left(\mathrm{T}=25^{\circ} \mathrm{C}\right) \%$ & 100 & 88.85 & 78.73 \\
\hline Change in $\mathrm{fr} \%$ & 0 & -11.1 & -21.2 \\
\hline
\end{tabular}




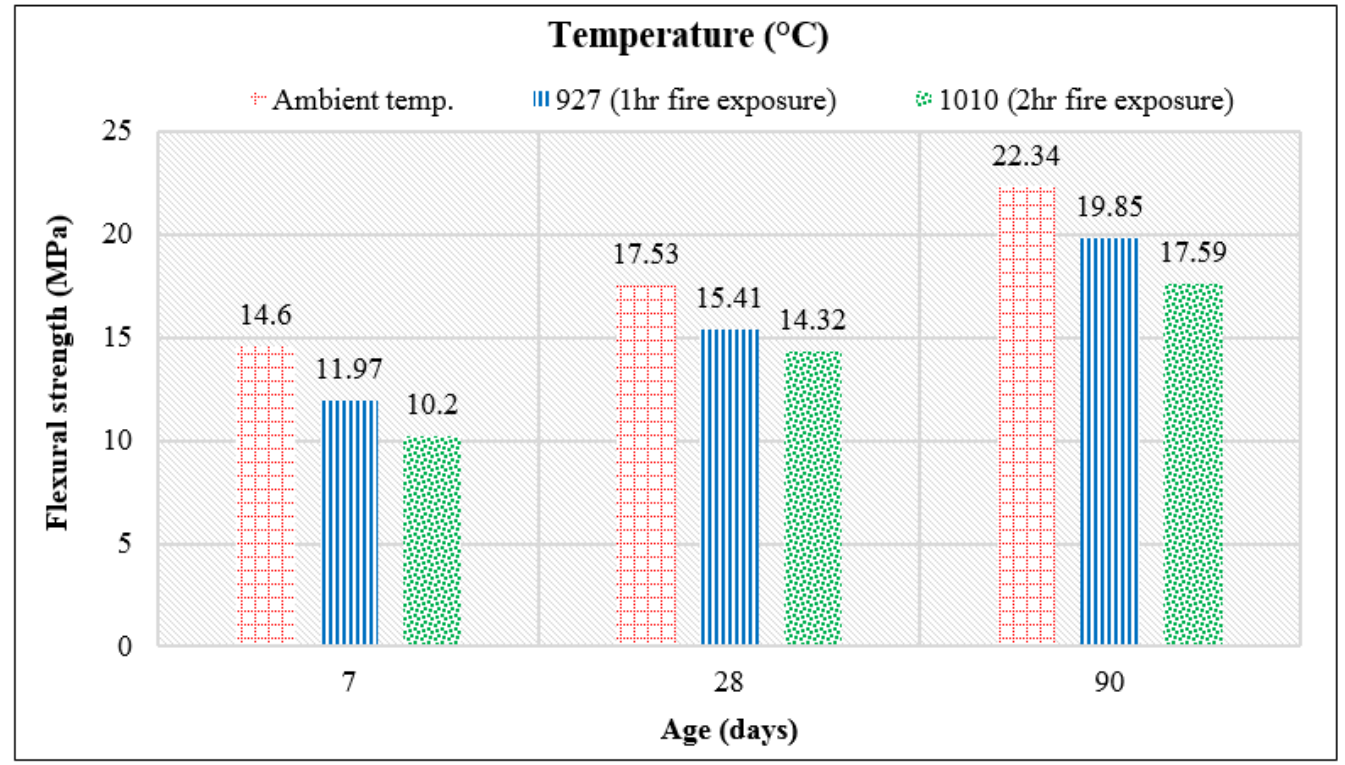

Figure 14. Fire flame effect on Flexural strength of SIFCON samples

It is evident from Figure 14, that all SIFCON specimens have less reduction in flexural strength as compared with that of others mechanical properties, this is due to the superior bond ability between steel fiber and cement paste, and that reducing the cracks of the concrete due to its inside contraction, where the drying of the specimen results in a reduction in the measured modulus of rupture.

\section{Conclusions}

The following conclusions can be drawn on the basis of the test results of this study and within the limitations of the test parameters:

- Results show that the decrease of the elastic modulus values at the same fire flame temperatures is more significant than that of the compressive force.

- The drastically reduction of compressive strength, flexural strength and elastic modulus took place with increasing temperature from 927 to $1010{ }^{\circ} \mathrm{C}$ due to the loss of moisture content and decomposition of C-S-H and $\mathrm{CH}$ hydrates.

- After burning, the fire exposed samples of SIFCON maintained its shape, and no evidence of spalling was found.

- By comparison the results of SIFCON residual compressive strength and elastic modulus after fire flame exposure with the results calculated from experimental values of other type of concrete collected from many other studies. It's clear that SIFCON performs better than other types of concrete at high temperatures.

- Flexural strength of SIFCON specimens have less reduction as compared with that of others mechanical properties.

- For the studied period of exposure to fire flame in this study, the compressive strength - reduction curve, recommended by Euro Codes CEN $(1993,1994)$ is in better agreement with the test results rather than CEB (1991) strength - reduction curve.

- The residual compressive strength, flexural strength and elastic modulus at $1010{ }^{\circ} \mathrm{C}$ were in the range of $(58.4$ to $80.1 \%),(81.6$ to $78.7 \%)$ and (30.4 to $32.8 \%)$ respectively.

\section{Acknowledgement}

The authors wish to express their gratitude and sincere appreciation to the head and staff of Civil Engineering Department in Babylon University. I would like also to express my special appreciation to staff of construction materials laboratory at the civil engineering department for presenting all the facilities to finish this work.

\section{Conflicts of Interest}

The authors declare no conflict of interest. 


\section{References}

[1] Khamees, Shahad S., Mohammed M. Kadhum, and Nameer A. Alwash. "Effects of Steel Fibers Geometry on the Mechanical Properties of SIFCON Concrete." Civil Engineering Journal 6, no. 1 (January 1, 2020): 21-33. doi:10.28991/cej-202003091450.

[2] Wang, M.L., and A.K. Maji. "Shear Properties of Slurry-Infiltrated Fibre Concrete (SIFCON)." Construction and Building Materials 8, no. 3 (September 1994): 161-168. doi:10.1016/s0950-0618(09)90029-0.

[3] Gilani, Adel Mohamed. "Various durability aspects of slurry infiltrated fiber concrete." PhD diss., Middle East Technical University (2007).

[4] Sonebi, Mohammed, Lucie Svermova, and Peter JM Bartos. "Factorial design of cement slurries containing limestone powder for self-consolidating slurry-infiltrated fiber concrete." Materials Journal 101, no. 2 (2004): 136-145.

[5] Sonebi, M., L. Svermova, and P. J. M. Bartos. "Statistical Modelling of Cement Slurries for Self-Compacting SIFCON Containing Silica Fume.” Materials and Structures 38, no. 1 (January 2005): 79-86. doi:10.1007/bf02480578.

[6] S.-K. Kim and J.-H. Choi, "Compressive and Tensile Strength Properties of Slurry Infiltrated Fiber Concrete.” Journal of the Korea Concrete Institute 18, no. 5 (October 31, 2006): 703-708. doi:10.4334/jkci.2006.18.5.703.

[7] Pradeep, T., and S. Sharmila. "Cyclic behavior of RC beams using SIFCON sections." International Journal of Innovative Research in Science, Engineering and Technology 4, no. 9 (2015): 9172-9177.

[8] Kadhum, Mohammed. "Prediction of Mechanical Properties of Reactive Powder Concrete by Using Artificial Neural Network and Regression Technique after the Exposure to Fire Flame.” Jordan Journal of Civil Engineering 9, no. 3 (July 1, 2015): 381399. doi:10.14525/jjce.9.3.3079.

[9] Al-Owaisy, Sallal Rashid, and Muhaned A. Shallal. "Strength and elasticity of steel fiber reinforced concrete at high temperatures." Journal of Engineering and Sustainable Development 11, no. 2 (2007): 125-133.

[10] Beglarigale, Ahsanollah, Çağlar Yalçınkaya, Hüseyin Yiğiter, and Halit Yazıcı. "Flexural Performance of SIFCON Composites Subjected to High Temperature." Construction and Building Materials 104 (February 2016): 99-108. doi:10.1016/j.conbuildmat.2015.12.034.

[11] Alkafaji, Mohammed Mansour Kadhum. "Structural Performance of Short Square Self Compacting Concrete Columns in Fire." Engineering and Technology Journal 33, no. 1 Part (A) Engineering (2015): 237-256.

[12] Hassan, Sawsan Akram. "Effect of Addition of Steel Fiber on the Compressive Strength of Composite Concrete Materials under High Temperatures (Experimental \& Statistical Work)." Journal of Engineering and Sustainable Development 10, no. 3 (2006): 60-69.

[13] Hashim, Ali Mudhafar, and Mohammed Mansour Kadhum. "Compressive Strength and Elastic Modulus of Slurry Infiltrated Fiber Concrete (SIFCON) at High Temperature." Civil Engineering Journal 6, no. 2 (February 1, 2020): $265-275$. doi:10.28991/cej-2020-03091469.

[14] Aslani, Farhad, and Morteza Bastami. "Constitutive relationships for normal-and high-strength concrete at elevated temperatures." ACI Materials Journal 108, no. 4 (2011): 355.

[15] Khaliq, Wasim, and Venkatesh Kodur. "Thermal and Mechanical Properties of Fiber Reinforced High Performance SelfConsolidating Concrete at Elevated Temperatures." Cement and Concrete Research 41, no. 11 (November 2011): 1112-1122. doi:10.1016/j.cemconres.2011.06.012.

[16] Aslani, Farhad, and Bijan Samali. "Constitutive Relationships for Steel Fibre Reinforced Concrete at Elevated Temperatures." Fire Technology 50, no. 5 (January 16, 2013): 1249-1268. doi:10.1007/s10694-012-0322-5.

[17] Abdulraheem, Mustafa S., and Mohammed M. Kadhum. "Experimental and Numerical Study on Post-Fire Behaviour of Concentrically Loaded Reinforced Reactive Powder Concrete Columns.” Construction and Building Materials 168 (April 2018): 877-892. doi:10.1016/j.conbuildmat.2018.02.123.

[18] Kadhum, Mohammed Mansour. "Effect of burning by fire flame on the behavior of reinforced concrete beam models." Journal of University of Babylon 21, no. 5 (2013): 1486-1506.

[19] Kadhum, Mohammed M., Mahdi S. Essa, and Nada M. Fawzi. "Behaviour of Fire Exposed Reinforced Concrete Columns." Journal of Engineering 17, no. 3 (2011): 412-429.

[20] Kadhum, Mohammed Mansour, and Zaid Ahmed Mohammed. "Predict the Ultimate Moment Capacity of Reactive Powder Concrete Beams Exposed to Fire Flame Using Artificial Neural Network and Multiple Linear Regression Models." International Journal of Engineering and Technology 9, no. 3 (June 30, 2017): 2637-2649. doi:10.21817/ijet/2017/v9i3/1709030347. 